The vision of the right eye was $6 / 24$ and the weakness of the external rectus was much less.

There are several interesting points in the case :-

(1) The sudden onset of intense pain, which was probably due to the increase of tension.

(2) The association of greatly increased tension with papillitis.

(3) The paralysis of the external rectus.

Several cases of external rectus palsy and papillitis in association with accessory sinus suppuration have been described. Ewing and Sluder ${ }^{3}$, in a paper on this complex, attribute the paresis to the relation of the abducens, which lies lowest in the sphenoidal fissure, to the ethmoidal cells.

It is possible that the increased tension was produced by the pressure of the odematous orbital tissue on the ophthalmic veins.

\title{
REFERENCES
}

I. Killian.-Accessory Sinuses 1913, p. 304 .

2. St Clair Thomson. - Lancet, I916.

3. Ewing and Sluder. -Ophthalmoscope, 1915, Vol. XIII, p. 469.

\section{PROTECTION OF THE EYE IN WARFARE*}

\section{BY}

\author{
R. R. CRUise, C.V.O., \\ CAPTAIN R.A.M.C. (T.).
}

WHEREVER the question of body armour arises, the two discordant factors of efficacy and practicability have to be faced.

The steel helmet was the first great and effective compromise between these two factors, and even then it required a rigid discipline to enforce its usage upon a reckless and reluctant soldiery.

The measure of protection against injuries to the head afforded by the steel helmet will, it is hoped, find a parallel in the case of the eye, in the visor which I have designed, and which the War Office has accepted and adopted, and which is now on its trial on an extensive scale.

But before describing the visor, it is necessary to consider the types of injury to which eyes are liable in warfare.

From the point of view of protection, eye injuries may be divided into two classes :-
(a) preventible; (b) non-preventible.

*Communicated to the 1917 Congress of the Ophthalmological Society of the United Kingdom. The full communication will be published in the Society's Transactions. 
The simplest instances are, of $(a)$ a small shell splinter penetrating the globe ; of $(b)$ a bullet traversing both orbits.

The latter class needs no further attention. The former class demands most earnest consideration by the ophthalmic world and the military authorities.

To obtain an accurate conception of the extent of this class, one requires statistics covering a large number of cases examined carefully and critically within a brief lapse of time of the injury. Facial wounds heal rapidly, and evidence quickly disappears, so that even under the most favourable circumstances, there must always be a large category of injuries where the verdict between preventible and non-preventible must remain non-proven.

But still there will also be a much larger class where the evidence is clear as to the preventible nature of the damage:

Cases where the cornea is perforated, the iris prolapses, and a septic panophthalmitis results.

Cases where a foreign body has had sufficient energy to penetrate the globe, and remain there.

Contusions of the globe producing a varied and common picture of dislocated lens, and traumatic cataract, iridodialysis, intra-ocular hæmorrhage, and retinal lesions-in this respect I would say, by way of parenthesis, that I have been much surprised by the relatively few cases of detachment of the retina that have occurred in my experience of war injuries.

These and many similar injuries are the result of any form of explosive-shell, grenade, or bomb-sending every kind of matter, mineral, vegetable, and animal, into the eyes in a shower of particles of every size and shape.

The majority of the injuries caused by this type of casualty are due to small particles.

Morax and Moreau, working at the Lariboisière Hospital in Paris, estimated that 54 per cent. of the casualties to eyes, in a series of 486 cases of injuries by shell, grenade or bomb, were caused by small particles; and as the result of a critical examination of 698 cases, conclude that 50 per cent., or one-half, of all eye injuries could be prevented by some sort of gauze shield (Ann. d'Ocul., August, 1916).

My own experience, and that of others to whom I have spoken, puts the percentage higher; but even if one estimates that 50 per cent. of all eye casualties are caused by small particles, and that there is a practical form of protection against them, it will be admitted that an imperative duty lies before us to insist on expediting the supply of a practical form of ocular protection to our Army.

My ophthalmic resident, Captain W. L. Holyoak, has assisted me in examining a series of cases at the 3rd London General Hospital, 
Wandsworth, and at St. Dunstan's, where, by the courtesy of that indefatigable worker on behalf of the blind-Sir Arthur Pearson-we examined 100 cases, or 200 eyes.

The question to decide was what we should consider preventible. We took a deliberately modest view of the stopping power of the visor of chain mail.

We excluded as non-preventible all injuries by bullets; injuries by shell fragments of sufficient strength to fracture any bones in the orbital, nasal, or malar region; injuries producing deep scarring of the face in the vicinity of the eye; injuries producing extensive scarring of intra-orbital contents, as evidenced by shrinking sockets; severe concussion effects where the globe was outwardly uninjured.

We classified as preventible :-

Cases where the history and appearance made it reasonable to suppose that the injury was caused by a small particle of low energy, causing loss of sight by perforation or laceration of the globe.

Corroborative evidence was afforded by slight superficial skin injuries in the neighbourhood.

We classified as doubtful 16 cases, but we finally decided to include all of these among the non-preventible.

Even so, the percentages worked out:-Preventible, 52 per cent. ; non-preventible, 48 per cent. These figures are for 200 consecutive eyes at St. Dunstan's only, and are remarkable when one considers that they are figures taken from an institution to which only the most serious cases are sent, involving loss of sight of both eyes.

When we came to examine the figures from the 3rd London General Hospital, at Wandsworth, the percentage of preventible injuries was still higher.

All the cases were of comparatively recent date, and the evidence to form a decision upon was more definite, and probably the conclusions were more accurate.

As, however, we have only recently begun to consider percentages, our numbers are insufficient for a final statement; but we propose at a later date to give fuller figures, when further evidence has been collected.

We have examined 120 eyes in the wards at present, and classify them as follows:-Preventible, 65 per cent.; non-preventible, 35 per cent.

Added to the figures obtained at St. Dunstan's, this yields a total of 320 eyes examined, with the result :-Preventible, 58 per cent.; non-preventible, 42 per cent.

So that, if a reduced estimate is made that 50 per cent. of all eye injuries are preventible by a protection such as that afforded by the visor, that would accord with the figures and opinion of Morax and Moreau, quoted before: and, in our opinion, would be an understatement, rather than an exaggeration of the facts. 
The visor (see Figure) consists of a transparent mesh of steel rings, so closely linked together that only the most minute particle could pass through its meshes, and then only if it were struck at

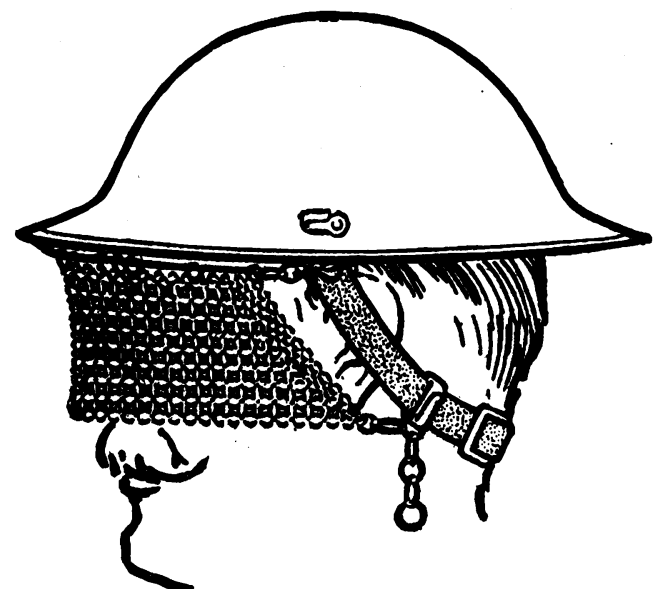

right angles to the plane of its surface; a tangential blow would meet with a practically continuous barrier of steel.

The visor is fastened to the helmet. It is therefore not a separate piece of equipment to be remembered, and attached to an already overloaded body.

When not required, the visor can be thrown up on to the brim of the helmet, and lowered again as occasion requires, by the simple process of unhooking a chain, and refastening to another hook.

A chemical process renders the links rust-proof.

\title{
PAPILLEDEMA IN RELATION TO GUNSHOT FRACTURE OF THE MANDIBLE
}

BY

\author{
G. F. C. Wallis, \\ MARGATE.
}

THE papillœdema of the optic nerve seen in the patient whose history is here recorded, presents two rather interesting features: first, in that the cause was apparently a local meningitis from infection through a traumatic fissure of the glenoid fossa; and, secondly, that the optic nerve was not involved until two months after the original wound was received, being excited in all probability by attempts to remove sequestra of the mandible. The patient is also one of the many examples this war has provided of extraordinary tenacity of life after severe injury. 